\title{
Evidence based Practices for Drug Abuse Information Management and Awareness Approaches
}

\author{
Joyce Philipo Mnunguli 1*, Michael Kisangiri ${ }^{1}$ \\ ${ }^{1}$ COCSE (School of Computational and Communication Science and Engineering) The Nelson Mandela African Institution \\ of Science and Technology (NM-AIST), TANZANIA
}

*Corresponding Author: mnungulij@nm-aist.ac.tz

Citation: Mnunguli, J. P. and Kisangiri, M. (2018). Evidence based Practices for Drug Abuse Information Management and Awareness Approaches. Journal of Information Systems Engineering \& Management, 3(4), 31. https://doi.org/10.20897/jisem/3942

Published: November 10, 2018

\begin{abstract}
The harmful use of illicit drugs "Drug abuse" is the most frequent problem in the world. Khat, heroin, cocaine, cigarette and cannabis have been the most common used drugs in African countries, for instance Tanzania. Youth have been identified as the most vulnerable group and highly affected. Drug abuse results into economic, social and health effects including; mental retardation, lung diseases, heart diseases and Human Immunodeficiency Virus (HIV), disorders in adolescence, young adults and the general public. Several awareness and initiatives program were done by the government and private sectors in bringing awareness on the effects of drug abuse through community and school based education, distribution of brochures as well as media. However, in Tanzania, management of addict's data, statistics about addicts, storage and accessibility of drug abuse information are conducted on paper based approaches resulting into several problems such as damage of data and loss of information, time consumption in data collection, delay in reporting, and difficulties in reaching the large number of people during awareness programs. This paper presents the evidence of practices, awareness and information management on drug abuse, case of Dar es Salaam and Arusha major cities in Tanzania, with web and mobile application designed solution for drug abuse data management and awareness creation.
\end{abstract}

Keywords: drug abuse, awareness, addict data collection, addict information management, drug addiction

\section{INTRODUCTION}

The United Nations Office of Drug and Crime (UNODC) recognizes drug abuse as a frequent problem in the world and works on assisting members of states in the struggle against illicit drugs (UNODC, 2014). The increase in the number of people who misuse drugs reduces the manpower of the country. Drug abuse refers to the consumption or misuse of illegal drugs (Johnson et al., 2007). Other studies describe drug abuse as the desire to use or increase the amount of substance (Needle et al., 2006). Causes of drug misuse include; peer pressure, depression, low self-esteem, easy accessibility and availability of illegal drugs. The use of illegal drugs results in several effects including health, social and economic impact (Singer, 2008). Health impact include; mental retardation, lung diseases, heart diseases and HIV.

In addition, the use of illegal drugs results in disorders in adolescence, young adults and the general public (Balsa et al., 2010). It is estimated that over 29 million people who use illegal drugs suffer from drug use disorders, while injection being the popular method used, the statistics show about 14 million of people are injecting drugs (UNODC, 2016). Thus, the risk of HIV infection increases because of sharing of needles and syringe during the 
injections. It is estimated that one in eight people who were injecting drugs in 2015 were HIV victims which equates to 1.55 million of people who inject drugs living with HIV worldwide (UNODC, 2017).

Similarly, in Africa, there is an increase of illegal drugs usage from the traditional use of cannabis to other dangerous illegal drugs (Affinnih, 2002). The study shows that over 28 million people in Africa are using illegal drugs, this is due to the easy availability of illegal drugs and drug trafficking activities (UNODC, 2016). Common illegal drugs used in Africa include; khat, heroin, cocaine and cannabis. However, cannabis is mostly used (UNODC, 2013). Youth have been identified as a vulnerable group of people who are engaging in drug abuse issues (UNODC, 2013). Nevertheless, there are few suggested ways to help prevention of drug abuse activities, including; provision of education to the youth and community, and the provision of consultation and treatment to addicts instead of detaining them (Miller et al., 2008).

Tanzania as one of the country found in Eastern African, the number of youth affected due to the use of illegal drugs is higher. Despite, the fact that, youth are the most highly considered as the manpower of the nation, but is the most vulnerable group in engaging with drug abuse (Masibo et al., 2013). Drugs like cannabis, heroin, cocaine, khat, alcohol, and cigarette are most frequently drugs used by $5-12 \%$ of youth at the young age (Yusuph et al., 2016). The drug control commission (DCC) report of 2012 says that in Tanzania the number of addict ranges between 150,000 and 500,000 where 96\% were youth (DCC, 2012).

Apart from the government efforts in blocking the penetrations and distribution of illegal drugs within a country, still most of the drugs used are imported from Iran, India, Bolivia and Peru thus increasing the availability and accessibility of drugs within the community (DCC, 2013). On the other hand, cannabis is mostly cultivated in several regions of Tanzania such as; Arusha, Tanga, Mara and Kilimanjaro and some farmers have been claiming to use cannabis as traditional vegetables and eye medicine (DCC, 2013). However, the government has been destroying the cultivation since it highly contributes to the local business of illegal drugs and increases the usage.

Consequently, there are several strategies and initiatives done by government and private sectors in the creation of drug abuse awareness to the community through community based education programs conducted to a certain group of people, educational programs at different levels; primary, secondary and university with the goal of reducing the impact on misuse of drugs and excessive use of alcohol (Johnson et al., 2007). These kinds of education are insisted to be conducted continuously in order to increase awareness within the community.

The information and statistics about addicts, usage and accessibility of drugs, effects and preventions means such as education are vital to the government and private institutions in reducing the risk and rescuing the drug abuse effects. Currently, the information is being managed in a paper-based form whereby treatment centers submit patient's details and monthly reports to Drug Control Commission (DCC) in paper-based then stored in flat files. Hence, the whole process of collecting data, storage, reporting and awareness programs are conducted manually thus contributes to several problems, such as consumption of time, loss of files, delay in national reporting, and sometimes difficulties in reaching many people during awareness programs.

Therefore, this paper presents the evidence of practices, awareness and information management on drug abuse which is the results of data collection and analysis conducted in Dar es Salaam and Arusha, Tanzania. In addition, this paper provides a technological designed solution based on a web and mobile application purposely for providing awareness to the general public, data collection, storage and information reporting on drug abuse.

\section{RELATED WORK}

Presently, the use of Information and Communication Technology (ICT) has increased in solving real-life problem scenarios. Drug abuse is one of it, several efforts have been invested regarding awareness on drug abuse issues and how drug abuse information can be managed.

Gustafson et al. (2011) described the development of Alcohol Comprehensive Health Enhancement System Support (ACHESS) application, which provides interaction between addicts and practitioners. It is an embedded application in the smartphone devices. It has both static contents and interactive features. It provides a platform where patients interact, share their stories and have discussion (Gustafson et al., 2014). This application was intended for the people who are addicted. One among weaknesses of this application is that it has a bias as it used by the addicts only and not benefiting the community and government agencies.

Also, Marsch et al. (2014) developed a computerized based education system called the Therapeutic Education System (TES) that provides education on drug abuse issues. It has a self-training module whereby an individual has to listen audios and do some homework provided by the system, the other part on this application is for alcohol and drugs awareness which provides opportunities for people to learn about drug abuse issues, it also provides different courses on drug abuse issues (Marsch et al., 2014). Users need to register to a specific course then start training. It was intended to the addicts and not otherwise.

Furthermore, Substance Abuse and Mental Health Services Administration agency (SAMHSA) in the United States introduces Drug and Alcohol Services Information System (DASIS) which act as the source of drug and 
alcohol service information. It comprises of three datasets which include the inventory of Substance Abuse Treatment Services (I-SATS), the National Survey of Substance Abuse Treatment Services (N-SSATS) and the Treatment Episode Data Set (TEDS) (SAMHSA, 2008). I-BHS is responsible for listing all organized substance abuse and mental health treatment facilities, TEDS collect demographic treatment information of the patients and N-SSATS is responsible for doing the census on all facilities listed in I-BHS (SAMHSA, 2014). DASIS with its three data sets provides information on the mental health data and drug abuse. The system focus on providing survey information on drug abuse, treatment services programs and drug history information on people who are in treatment. It does not provide information awareness on the effects and prevention of drug abuse, no any interactivity among users and does not show treatment location to let people aware of where consultation and treatment services are provided.

Therefore, the study proposes development of the web and mobile based application for drug abuse information awareness, where mobile application will be used for data collection from rehab centers and a web application will provide interface for users to access information about the trends on the usage of illegal drugs, statistical reports on number of people receiving treatments, location of treatment centers as well as awareness program. In addition, a forum for users discussion on drug abuse issues.

\section{METHODOLOGY}

\section{Description of Study Area}

The cases for this study were Dar es Salaam and Arusha. Dar es Salaam is the largest and economic city in Tanzania. It is located in coastal Indian Ocean. The area of Dar es Salaam is $1,393 \mathrm{~km}^{2}$ (538 sq mi). According to Tanzania Bureau of Statistics (NBS) Dar es Salaam population is approximately 4.3 Million (NBS, 2017), it is formed by five districts; Kinondoni, Ilala, Kigamboni, Ubungo and Temeke. In addition, it comprises with the social, economic and industrial activities. Arusha is the city in northern eastern Tanzania with approximate population of 1.6 million (NBS, 2017). The area of Arusha region is $34,526 \mathrm{~km}^{2}$. It is located near the greatest national parks and game reserve in Africa, including; Kilimanjaro national park, Serengeti National Park, Ngorongoro Conservation Area, Lake Manyara National Park and Arusha National Park. Moreover, tourism activities are the major economic activities found in Arusha. Arusha is also, known as one among regions which cultivate cannabis (Yusuph et al., 2016). Despite the initiative on prevention of drug abuse in Tanzania but these two regions still have a high number of youth who are engaged in drug abuse activities (DCC, 2013).

\section{Sample Size and Sampling Technique}

The study involved a total of 252 residents in both regions whereas, 150 respondents were selected in five districts (Kinondoni, Ilala, Kigamboni, Ubungo and Temeke) within Dar es Salaam and 102 respondents in three districts (Monduli, Meru and Longido) in Arusha. Other stakeholder's institutions who were involved in the study include; Drug Control Commission (DCC), eight rehab centers located in Kigamboni, Pugu, Temeke, Mbezi, Kimara and Njiro, psychiatric from methadone clinic (Muhimbili Hospital and Temeke Hospital) and five NGO's. The NGO's include; Tanzania Network for People who use Drugs (TANPUD), peer group, Methadone Family against Drug Abuse (MEFADA), Youth Volunteers against Risk Behavior (YOVARIBE) and Women and Child vision (WOCHIVI). Simple random sampling technique was used to get the representative sample of the community. This technique was used to give all respondents equal chance to participate in the study, since the respondents had homogenous behaviors.

\section{Data Collection Methods}

During the study, data were collected in the period of two months, January to February in 2018. The study used questionnaires, interviews and observation as tools for data collection. Questionnaires were distributed to the youth of age between 18-40 years to gather general knowledge on drug abuse information and programs. Interviews and observations were conducted to the government and private institutions which were dealing with prevention of drug abuse, controlling and treatment of addicts in Tanzania. The institutions include; Drug Control Commission, eight rehab centers, five NGO's and two methadone clinic from Muhimbili and Temeke hospitals. The main objective was to understand how the current activities in dealing with controlling and prevention of drugs were being done especially awareness program to the community, how addict's data collected, stored and reported within the rehabs, methadone clinic (hospitals) and DCC. 


\section{Data Analysis Methods}

Both qualitative and quantitative data were obtained during the study through the interviews, questionnaires, and observations. Data were analyzed by using a descriptive method in $\mathrm{R}$ software and google sheet which provides management capabilities and administrative tool for high performance and data analytics.

\section{RESULTS AND DISCUSSION}

\section{General Awareness of the Drug Abuse Information}

The study sought to find out the certainty of general awareness on drug abuse information, it was found that about $74 \%$ of respondents in Dar es Salaam did not have enough knowledge on drug abuse information while $26 \%$ had a knowledge on drug abuse information, similarly in Arusha $73 \%$ of respondents did not have enough knowledge of drug abuse information while $27 \%$ had enough information on drug abuse issues.

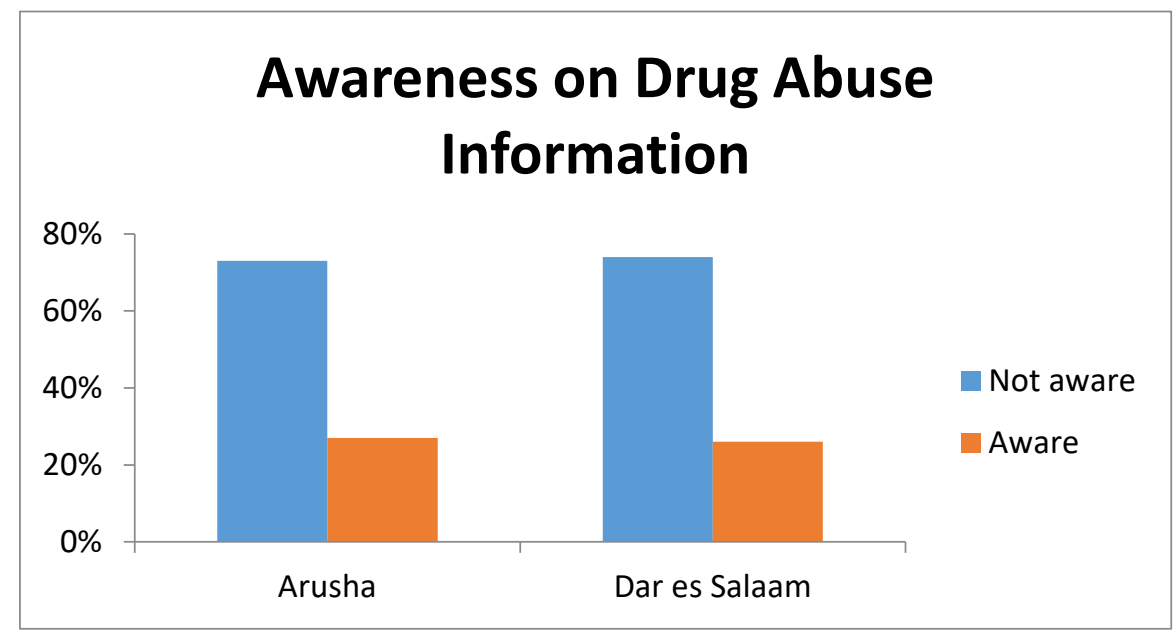

Figure 1. Awareness in Dar es Salaam and Arusha

\section{Awareness on the Treatment Location}

To know the location for consultation and treatment services is vital in increasing the awareness of addicts treatment center within a society. During the study it was found that in Dar es salaam $78 \%$ of the respondents were not aware of the treatment location, and only $22 \%$ knows where to get treatment and consultation on drug abuse issues, whereas in Arusha $79 \%$ of respondents did not know where to get consultation service or treatment for addicts while $21 \%$ knows where to get treatment services.

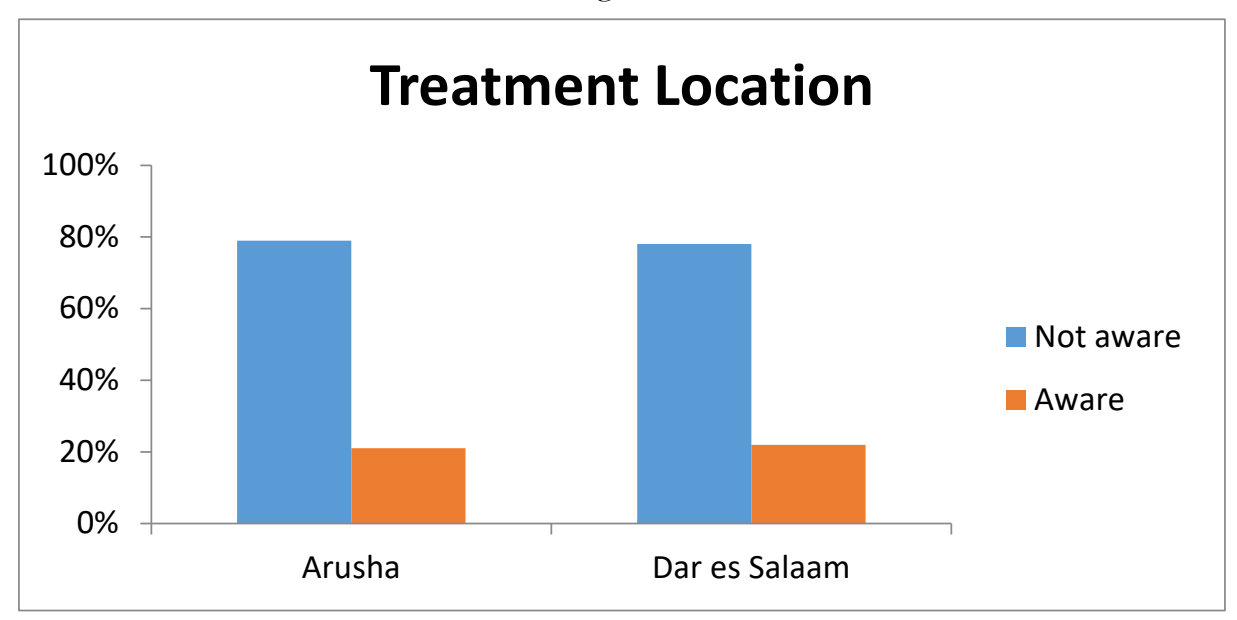

Figure 2. Awareness on treatment location in Dar es Salaam and Arusha

\section{Availability of Drug Abuse}

Availability of illegal drugs is also a factor that contributes to the increase of the usage of illegal drugs in the community. The research revealed that the availability of illegal drugs influence more people to engage themselves in drug abuse activities such as trafficking and other small business conducted locally within the community thus brings more people to use drugs. Generally, $48 \%$ of respondents agreed that there is easy accessibility of illegal drugs, $28 \%$ respond on fairly easy accessibility and availability, while 15\% respond on fairly difficult and $9 \%$ 
respond on difficult. The higher percentage shows that there is the easy availability of illegal drugs among the community and this influence youth to engage in drug abuse activities.

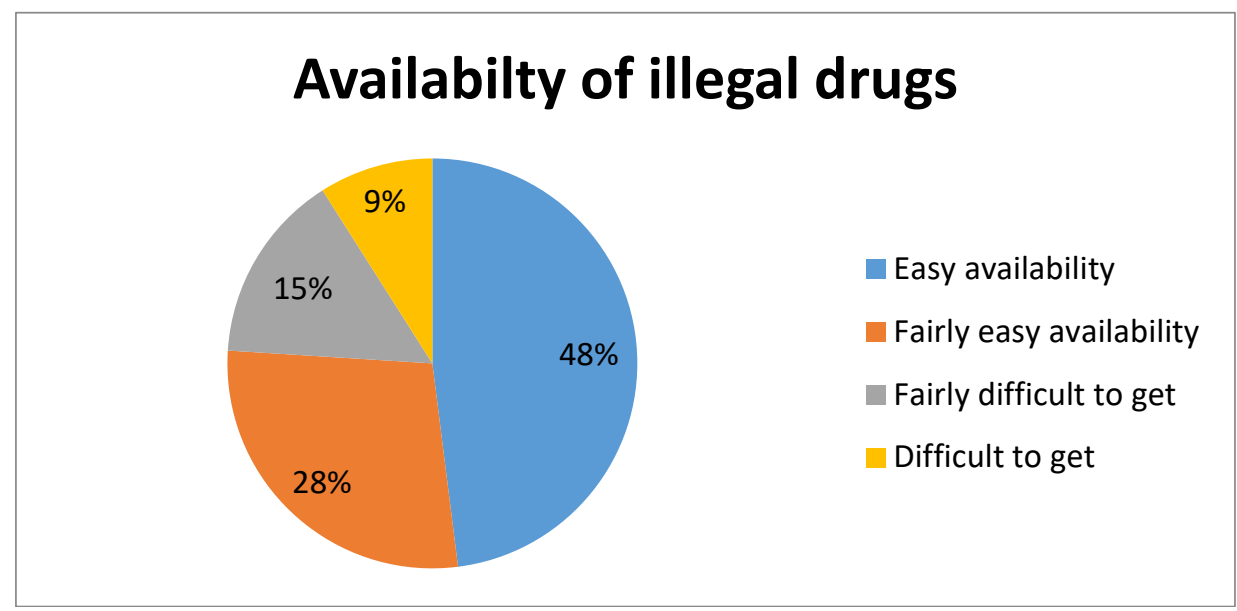

Figure 3. Accessibility of illegal drug

\section{Sources of Information on Drug Abuse}

The community uses media, friends and school program to get information. Media was the most popular source of information with $45 \%$ of usage compared to the school's program which were $24 \%$ and friends $32 \%$. Nevertheless, the study found that despite the availability of sources of information in the community, drug abuse information was rarely provided through the media, which was the most frequently used as the source of information access.

\section{Source of drug abuse awareness}

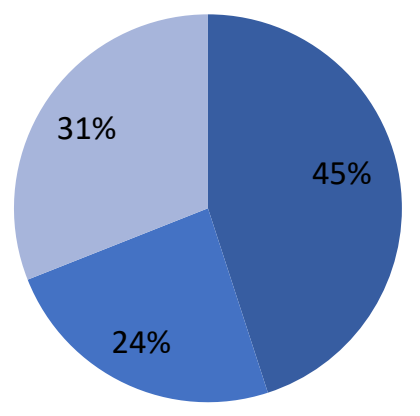

Media

- Friends

Schools

Figure 4. The sources of information

\section{Overview of the Existing System}

Interviews and observations were also conducted by the study and helped in examining how drug abuse activities were conducted within DCC, NGO's, rehab centers and methadone clinic. Currently, NGO's provide awareness manually by going into different places such as schools, neighborhood while distributing awareness materials in form of brochures, they also conduct training programs and advertisement which were conducted via radio and television.

However, the study found that awareness programs in schools and places where addicts found were conducted only once per week due to the lack of resources, apart from that they were also obligated to take addict to the methadone clinic and rehab centers for treatment and consultation services. Also, it was observed that larger group of people were gradually felling into drug addiction due to the lack of awareness and prevention programs, most of NGO's focus their effort in taking addicts to the therapy while leaving a large group of people behind without awareness. These were due to the little involvement of ICT tools in their operations.

The study revealed that data collection from several rehab centers were conducted in paper-based whereby treatment centers record details of patients (addicts) on papers and submit to the Drug Control Commission (DCC) office monthly and so it was hard to get accurate information of patients found in treatment centers. The study found that $52 \%$ of addict's data submitted by rehab centers were inaccurate, while $48 \%$ were the accurate data. As was the fact, sometimes led DCC personnel to work around the centers to collect the required information for 
national reporting. However, the DCC itself kept the collected information on flat files which resulted in damage or loss of information and delay in generating general drug abuse report. For instance, the number of damaged files in 2017 was estimated to be 14 (40\%) out of 36 paper files (monthly reports) collected from 8 treatment center, this is due to misallocation of files. On the other hand, it was discovered that $80 \%$ of the addicts treated at the rehab center were engaged in drug abuse before without knowing the side effects of using illegal drugs. All respondents from different rehabs acknowledge that drug abuse is still a big challenge in the country and there was lack of awareness on the drug abuse issues. Furthermore, the study also observed that $96 \%$ of rehab activities were conducted in paper based as they had no any ICT tool such as a database for data storage and manipulations of data hence data were lost due to unavoidable circumstances.

Therefore, the study has proved the need for ICT tool to support data collection, storage and provide awareness on the effects and prevention of drug abuse. This will enable scholars, professionals, policy-makers and other stakeholders to get more information on drug abuse issues including trends of the usage of illegal drugs and statistics on the number of patients who are on treatment.

\section{DESIGNED SOLUTION}

Based on the study findings, several problems on drug abuse information awareness and addict's data collection were identified, for instance; loss and damage of data, consumption of time during addict data collection, delay in reporting, and sometimes difficulties in reaching large number of people during awareness programs. Therefore in solving the mentioned problems the study proposes an integrated web and mobile based application for drug abuse information awareness.

The mobile application side will be used as data entry tool for daily data collection and reporting of patient details from the rehab centers and methadone clinic and submits to the central database. This tool will provide an easiest way of collecting information and providing the statistics on the most illegal drugs used and the number of patients on treatment. On the other hand a web application with an interface allowing information access to all users including; the drug control commission, rehab centers, NGO's, and researchers. Moreover the solution will allow user participation through push message technique where short stories or testimonies and awareness messages on the drug addiction will be disseminated. Also through asking question and responses. In addition, the designed solution will provide the easiest way in locating nearby treatment or consultation center.

The proposed study designed solution architecture will be potentially contribute in drug abuse data management and awareness creation to the general public of Tanzania and world at large.

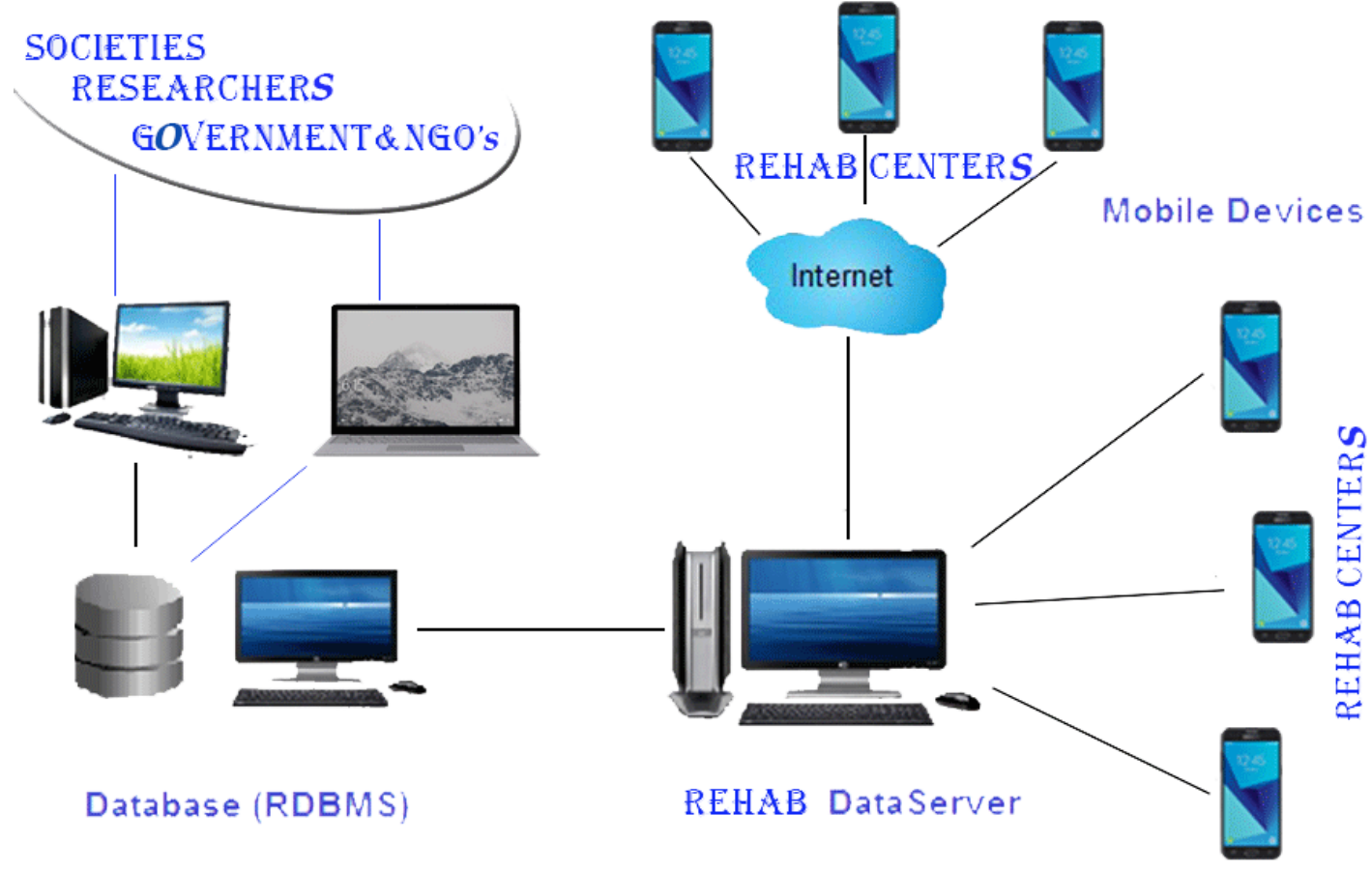

Figure 5. The designed solution 


\section{CONCLUSION}

The paper has presented the overview of the existing challenges on drug abuse sector and the analysis to show the extent of the problems on drug abuse such as awareness issues, treatment center location, data collection and storage problems in Tanzania. The study shows that there is inadequate drug abuse information within the community. Most of the people do not have enough knowledge on drug abuse issues (location of treatment center, effects and prevention of drug abuse), on the other hand collection and storage of patients data are being done in paper based which results into the loss of information and the delay on providing national reports. The presence of ICT tool plays a big role in reducing the challenges such as reducing the number of people who are using drugs, relapse prevention, reaching limited people who cannot participate in service, helping people remotely and providing drug abuse information to the public such as researchers, policy-makers and the government. Furthermore this paper presented a brief description on the design of web and mobile application as proposed ICT solution for optimizing the operations of drug abuse issues.

Future work will involve full design and development of the integrated solution of mobile application for data collection and a web application for drug abuse information awareness. Geographical mapping of treatment centers will be done in identifying centers which provides treatment and consultation on drug abuse issues. This will involve the use of several tools and software, which include android studio, JavaScript, XML, Hyper Text Markup Language (HTML), Hypertext Preprocessor (PHP), JAVA, MySQL and Dreamweaver.

\section{REFERENCES}

Affinnih, Y. H. (2002). Revisiting Sub-Saharan African Countries' Drug Problems: Health, Social, Economic Costs, And Drug Control Policy. Substance Use \& Misuse, 37(3), 265-290. https://doi.org/10.1081/JA-120002479

Balsa, A. I., Gandelman, N. and Porzecanski, R. (2010). The Impact of ICT on Adolescents' Perceptions and Consumption of Substances. IDB Working Paper Series, 1-21. Available at: http://idbdocs.iadb.org/wsdocs/getdocument.aspx?docnum $=35449433$

DCC. (2012). Taarifa ya hali ya dawa za kulerya ya mwaka 2011 (The drug and prevention of illicit trafficking report 2011). Da es Salaam Tanzania. Available at: http:/ /www.pmo.go.tz/

DCC. (2013). Taarifa ya hali ya dawa za kulerya ya mwaka 2011 (The drug and prevention of illicit trafficking report 2011). Dar es Salaam Tanzania.

Gustafson, D. H., Mctavish, F. M., Chih, M., Atwood, A. K., Johnson, R. A., Boyle, M. G., .., Shah, D. (2014). A Smartphone Application to Support Recovery From Alcoholism A Randomized Clinical Trial, 53706. https://doi.org/10.1001/jamapsychiatry.2013.4642

Johnson, K., Courser, M., Holder, H., Miller, B., Ogilvie, K., Moore, R.., ..., Saylor, B. (2007). A Community Prevention Intervention to Reduce Youth from Inhaling and Ingesting Harmful Legal Products. Journal of Drug Education, 37. https://doi.org/10.2190/DE.37.3.b

Marsch, L. A., Ph, D., Guarino, H., Ph, D., Acosta, M., Ph, D., ..., Edwards, J. (2014). Journal of Substance Abuse Treatment Web-based behavioral treatment for substance use disorders as a partial replacement of standard methadone maintenance treatment. Journal of Substance Abuse Treatment, 46(1), 43-51. https://doi.org/10.1016/j.jsat.2013.08.012

Masibo, R. M., Mndeme, E. and Nsimba, S. E. D. (2013). An assessment of knowledge, attitudes and practices of psychoactive substance use among secondary school students in Dodoma Municipality, Tanzania. American Journal of Research Communication, 1(4), 200-240. Available at: https://www.usa-jornals.com

Miller, B., Ph, D., Ogilvie, K., Moore, R., Ph, D., Collins, D. and Ed, M. A. (2008). A community prevention intervention to reduce youth from inhaling and ingesting harmful legal products. NIH Public Access, 37(3). https://doi.org/10.2190/DE.37.3.b

NBS. (2017). Tanzania Total Population by District - Regions -2016-2017. Tanzania Total Population by District Regions -2016-2017. Available at: http:/ /www.nbs.go.tz/nbs/takwimu/census2012/Tanzania_Total_Population_by_District-Regions2016_2017r.pdf

Needle, R., Kroeger, K., Belani, H. and Hegle, J. (2006). Substance abuse and HIV in Sub-Saharan Africa. African Journal of Drug \& Alcohol Studies, 5(2).

SAMHSA. (2008). About Dasis. Available at: https://wwwdasis.samhsa.gov/dasis2/aboutdasis.htm (Accessed 24 April 2018)

SAMHSA. (2014). Treatment Episode Data Set (TEDS). SubStance, (0930), 1995-2005. https:// doi.org/10.3886/ICPSR24280.v6

Singer, M. (2008). Drugs and development: The global impact of drug use and trafficking on social and economic development. International Journal of Drug Policy, 19(6), 467-478. https:/ / doi.org/10.1016/j.drugpo.2006.12.007 
UNODC. (2013). World Drug Report 2013. United Nations publication, Sales No. E. 13.XI.6 (Vol. 2013). https://doi.org/10.1002/yd.20002

UNODC. (2014). World Drug Report 2014. United Nations Publication. Available at: https://www.unodc.org/documents/data-and-analysis/WDR2014/World_Drug_Report_2014_web.pdf

UNODC. (2016). The world drug abuse report. United Nations publication. Available at: https://www.unodc.org/doc/wdr2016/WORLD_DRUG_REPORT_2016_web.pdf

UNODC. (2017). World drug report 2017: Global overview of drug demand and supply. United Nations publication. Available at: https://www.unodc.org/wdr2017/field/Booklet_2_HEALTH.pdf

Yusuph, K. and Negret, I. (2016). Adolescents and Drug Abuse in Tanzania: History and Evolution, 7(2), 1-10. https://doi.org/10.9734/AIR/2016/24897 